\title{
Metabotropic Modulation of Motoneurons by Scratch-Like Spinal Network Activity
}

\author{
Aidas Alaburda and Jørn Hounsgaard \\ Department of Medical Physiology, Panum Institute, University of Copenhagen, DK 2200 Copenhagen N, Denmark
}

Glutamate is the main excitatory transmitter in the spinal motor network. The excitation is to a large extent mediated by ionotropic receptors, but glutamate also activates metabotropic receptors. In motoneurons in spinal cord slices the activation of group I metabotropic glutamate (mGlu1) receptors leads to facilitation of $\mathrm{Ca}_{\mathrm{V}} 1.3 \mathrm{~L}$-type calcium channels. Here we investigate whether this pathway is activated by motor network activity induced by natural sensory stimuli. The lumbar carapace and spinal cord were isolated from adult turtles. In this preparation, mechanical stimulation in the receptive field for the scratch reflex induced episodes of rhythmic motor network activity. During an episode the excitability of coactivated motoneurons increased. This increase was associated with an increased persistent inward current and was abolished by local blockade of either mGlu1 receptors or $\mathrm{Ca}_{\mathrm{V}} 1.3 \mathrm{~L}$-type calcium channels near the recording site. We conclude that glutamate released during spinal motor network activity excites motoneurons by parallel activation of ionotropic and mGlul receptors. The metabotropic facilitation of L-type calcium channels contributes significantly to this excitation. Our findings establish intrinsic modulation as an active component in the spinal motor network for limb movements.

Key words: spinal cord; glutamate; L-type $\mathrm{Ca}^{2+}$ channels; integrated preparation; modulation; motoneuron

\section{Introduction}

Plateau potentials and the underlying persistent inward current (PIC) now seem to be hallmarks of spinal motoneurons in adult terrestrial vertebrates (Perrier and Hounsgaard, 2000). Despite being studied intensely, their function and significance remain controversial and unsettled. Some studies emphasize a possible involvement in pathology such as spinal seizures (Kao and Crill, 1972; Davenport et al., 1977) cramps (Baldissera et al., 1991, 1994), and spasticity (Bennett et al., 2001a,b). In normal function PIC has been considered a mechanism for secondary range firing (Crill and Schwindt, 1984), bistability (Hounsgaard et al., 1984, 1988), gain control (Hounsgaard et al., 1986), boost of synaptic excitation (Lee and Heckman, 2000), and regulation of recruitment order (Delgado-Lezama et al., 1997). None of these proposals, however, is supported by direct experimental evidence during functional motor network activity. In fact, regenerative plateau potentials in spinal motoneurons are observed only when outward currents are reduced by blocking $\mathrm{Cl}^{-}$or $\mathrm{K}^{+}$channels (Hounsgaard and Kiehn, 1985; Hounsgaard and Mintz, 1988) or when PIC is enhanced (Hounsgaard and Kiehn, 1989).

In support of a functional role, plateau properties were found to be induced in spinal motoneurons by tonic activity in descending serotonergic and noradrenergic pathways (Conway et al., 1988; Hounsgaard et al., 1988; Lee and Heckman, 1999). The ability of motoneurons to generate plateau potentials therefore

\footnotetext{
Received June 3, 2003; revised July 2, 2003; accepted July 2, 2003.

We thank the Lundbeck Foundation, European Union, and Statens Sundhedsvidenskabelige Forskningsråd (Danish Medical Research Council).

Correspondence should be addressed to J. Hounsgaard, Department of Medical Physiology, Panum Institute, University of Copenhagen, Blegdamsvej 3, DK-2200 Copenhagen N, Denmark. E-mail: j.hounsgaard@mfi.ku.dk. Copyright $\odot 2003$ Society for Neuroscience $\quad 0270-6474 / 03 / 238625-05 \$ 15.00 / 0$
}

seemed to depend on external modulation from the brainstem (Hounsgaard et al., 1988). However, complex sensory motor behavior like scratching (Sherrington, 1906; Valk-Fai and Crowe, 1978) and swimming (Lennard and Stein, 1977) can be organized by the spinal cord deprived of descending modulation. This may indicate either that plateau properties are not essential for motor activity or that there are intraspinal mechanisms for the induction of PIC in motoneurons.

Recent experiments have shown that activation of metabotropic glutamate receptors also facilitates plateau potentials and PIC in spinal motoneurons (Delgado-Lezama et al., 1997; Svirskis and Hounsgaard, 1998). It is not known whether intrinsic spinal modulation of this kind occurs during motor network activity. The present experiments were conducted in an isolated preparation of the lumbar carapace and spinal cord of the adult turtle. This preparation generates a scratch-like motor network activity in response to mechanical stimulation in the receptive field for the scratch reflex (Keifer and Stein, 1983). We have investigated whether PIC is detectable in spinal motoneurons in the absence of descending modulation and whether it is modulated by synaptically released glutamate during network activity.

\section{Materials and Methods}

Integrated preparation. Red-eared turtles (Chrysemys scripta elegans; $n=$ 20) placed on crushed ice $2 \mathrm{hr}$ before surgery to induce hypothermic anesthesia (Melby and Altman, 1974) were decapitated. Experiments were performed at room temperature $\left(20-22^{\circ} \mathrm{C}\right)$ in a normal Ringer's solution containing (in mM): $120 \mathrm{NaCl}, 5 \mathrm{KCl}, 15 \mathrm{NaHCO}_{3}, 2 \mathrm{MgCl}_{2}, 3$ $\mathrm{CaCl}_{2}$, and 20 glucose, saturated with $98 \% \mathrm{O}_{2} / 2 \% \mathrm{CO}_{2}$ to obtain $\mathrm{pH}$ 7.6. After substitution of blood with normal Ringer's solution, transverse cuts were made to isolate carapace containing D4-D10 spinal cord segments (see Fig. 1A). The hip flexor nerves were exposed and cut. The D10 vertebra segment was cut. The vertebral laminas and spinal cord were 
removed 3-5 $\mathrm{mm}$ from the rostral end of the preparation. The caudal cut end of the carapace was glued to a Plexiglas platform and mounted in a holder. A small Plexiglas slab was glued to the carapace at the rostral cut edge, and a plastic tube for perfusion of the spinal canal was installed. Inlet and outlet needles were placed for local superfusion of the exposed caudal cut surface of the spinal cord. Adjustments were performed to secure laminar flow over the cut surface of the spinal cord, using a phenol red-containing Ringer's solution.

The surgical procedures complied with Danish legislation and were approved by the controlling body under the Ministry of Justice.

Recordings. Intracellular recordings in current-clamp and voltageclamp mode were performed with an Axoclamp-2A amplifier (Axon Instruments, Union City, CA). Glass pipettes were filled with a mixture of $0.9 \mathrm{M}$ potassium acetate and $0.1 \mathrm{M} \mathrm{KCl}$. To reduce electrode capacitance in voltage-clamp recordings, we coated the pipette tips with Sylgard. Voltage-clamp recordings were performed in discontinuous service mode at a sample rate of $5-8 \mathrm{kHz}$, with a gain of $0.7-1.5 \mathrm{nA} / \mathrm{mV}$ and a low-pass filter of $0.1 \mathrm{kHz}$. Intracellular recordings were obtained from motoneurons in segment D10. The recording electrode was lowered vertically into the motonucleus, which was clearly visible at the cut surface under a stereo microscope (see Fig. 1A). Recordings were accepted if motoneurons had a stable membrane potential more negative than -50 $\mathrm{mV}$. Data were sampled at $20 \mathrm{kHz}$ with a 12-bit analog-to-digital converter (Digidata 1200, Axon Instruments), displayed by means of Axoscope and Clampex software (Axon Instruments), and stored on a hard disk for later analysis.

Hip flexor nerve activity was recorded with a differential amplifier Iso-DAM8 (World Precision Instruments, Sarasota, FL), using a suction pipette. The bandwidth was from $100 \mathrm{~Hz}$ to $1 \mathrm{kHz}$.

Data analysis. The clockwise hysteresis in the current-voltage relation is estimated as the difference in current during ascending and descending voltage ramps at $-45 \mathrm{mV}$. Data were analyzed statistically by using a two-population (paired) Student's $t$ test (Microcal Origin software, Northampton, MA). Significance was accepted when $p<0.05$. Data are presented as the means \pm SEM.

Stimulation. Mechanical stimulation was performed with the firepolished tip of a bent glass rod mounted to the membrane of a loudspeaker. The duration, frequency, and amplitude of the stimulus were controlled with a function generator (Rosenberg, 1986).

Drugs. L-type $\mathrm{Ca}^{2+}$ channels were blocked with nifedipine $(20 \mu \mathrm{M}$; Sigma, St. Louis, MO). 7-(Hydroxyimino)cyclopropa[b]chromen-1acarboxylate ethyl ester (CPCCOEt) (100 $\mu \mathrm{M}$; Tocris, Ballwin, MO) was used to block the subtype 1 metabotropic glutamate receptor (mGluR1).

\section{Results}

Mechanically induced scratch-like motor network activity in the isolated carapace-spinal cord preparation

In the isolated carapace-spinal cord preparation brief mechanical stimulation, applied at the junction between pocket skin and carapace (Fig. 1A), induced rhythmic activity in the hip flexor nerve (Fig. $1 B, C$ ). Episodes of rhythmic activity could outlast the stimulus by several seconds (Fig. $1 C$ ). Intracellular recordings from ipsilateral D10 motoneurons and recordings from the hip flexor nerve were performed in parallel. During episodes of stimulus-induced rhythmic activity recorded in the ipsilateral hip flexor nerve, current-clamp recordings from motoneurons revealed increased synaptic activity and rhythmic depolarizations exceeding the threshold for action potentials (Fig. $1 B$ ). In voltage clamp these episodes were associated with alternating inward and outward currents as well as increased synaptic noise (Fig. 1C). The rhythmic depolarizations in current clamp and the inward currents in voltage clamp were in-phase with the bouts of hip flexor nerve activity (Fig. $1 B, C$ ). Taken together, the pattern of activity in the hip flexor nerve and in motoneurons is compatible with the fictive scratch seen in the spinal turtle in vivo (Stein and Grossman, 1980; Robertson and Stein, 1988). In the present
A

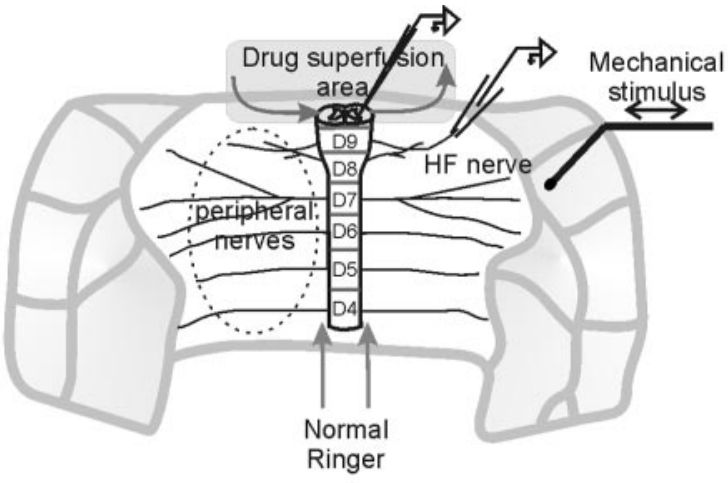

B
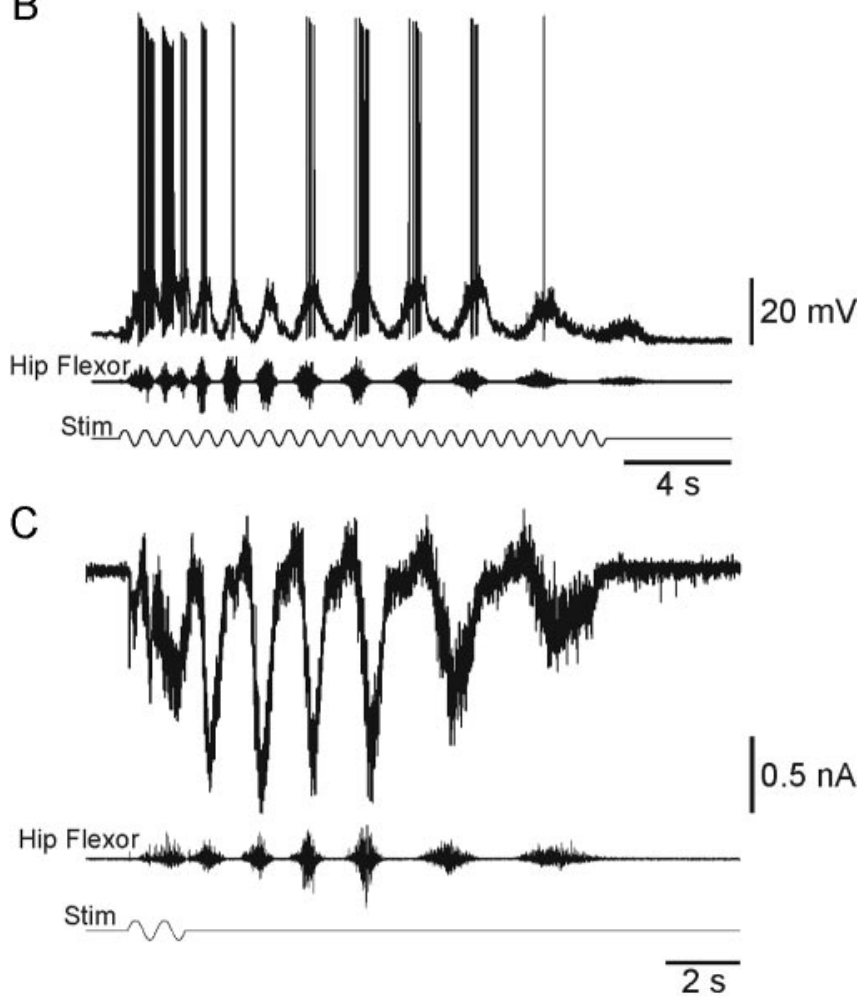

$0.5 \mathrm{nA}$

Figure 1. Integrated lumbar carapace-spinal cord preparation. $A$, Sketch of the integrated preparation and experimental setup. Shown is the response of a motoneuron and the hip flexor nerve to mechanical stimulus $(\mathrm{stim})$ recorded simultaneously in current-clamp $(B)$ and voltageclamp mode $(0)$

study we have used hip flexor nerve recordings to monitor spinal motor network activity.

\section{Network activity increases motoneuron excitability by facilitating a PIC}

We then tested whether the intrinsic response properties of motoneurons were affected by the scratch-like network activity induced by a mechanical stimulus. The excitability was monitored by the response to a depolarizing current pulse with a duration of $2 \mathrm{sec}$ applied every $20-25 \mathrm{sec}$. In the preparation at rest the amplitude of the current pulse was adjusted to induce a single action potential. After episodes of motor network activity the same depolarizing current pulse induced at least three action potentials $(5.36 \pm 0.66 ; n=11$; Figs. $2 A, 4 A)$. The increased excitability was observed for $>10 \mathrm{sec}$ after the membrane potential had relaxed to the resting level that was recorded before the induced network activity. This shows that motor network activity increased the 
A

\section{Control}
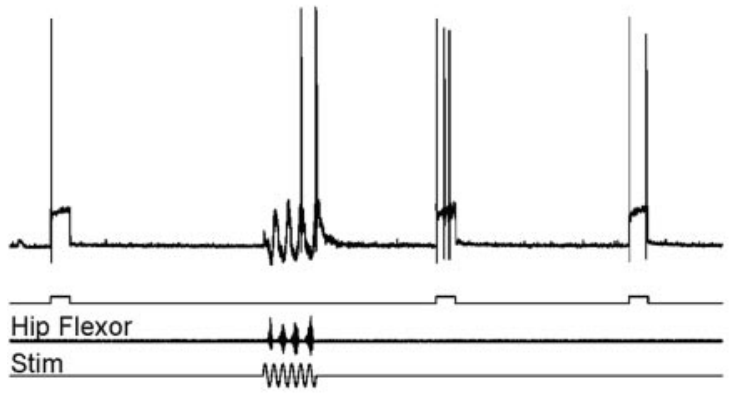

$B$

\section{+Nifedipine}
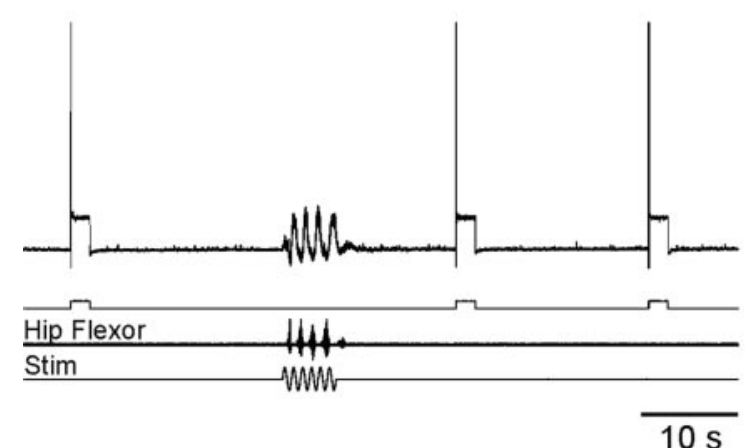

$20 \mathrm{mV}$

$12 \mathrm{nA}$

Figure 2. Motor network activity induces a nifedipine-sensitive increase in excitability of motoneurons. The excitability of motoneurons was tested by injecting suprathresholddepolarizing current pulses. Evoked episodes of network activity were followed by an increased excitability of recruited motoneurons lasting tens of seconds $(A)$. This increase in excitability was prevented by the local application of nifedipine $(20 \mu \mathrm{M})$ near the recording site $(B)$.

excitability of the motoneuron by mechanisms that did not affect the resting membrane potential.

When tested in voltage clamp with a triangular ramp command, the network activity facilitated a depolarization-induced inward current (Fig. 3A) and significantly increased the clockwise hysteresis in the current-voltage relation by $132 \pm 38 \%(p<$ $0.001 ; n=13$; Fig. $3 B$ ). From these observations we concluded that the increase in motoneuron excitability was attributable to facilitation of a slowly activating PIC rather than inhibition of a leak current (Fig. 3). The increased excitability in current clamp and the facilitation of the PIC in voltage clamp outlasted hip flexor activity by $>10 \mathrm{sec}$ (Figs. $2 \mathrm{~A}, 3 \mathrm{~A}$ ).

\section{Increase in excitability caused by facilitation of L-type $\mathrm{Ca}^{2+}$ channels}

Previous studies reported that plateau potentials and the PIC in spinal motoneurons are mediated by dihydropyridine-sensitive L-type $\mathrm{Ca}^{2+}$ channels (Hounsgaard and Mintz, 1988; Svirskis and Hounsgaard, 1998; Carlin et al., 2000a). We tested the involvement of L-type calcium channels in the network-induced increase in the excitability of motoneurons. The facilitatory effect of motor network activity was abolished by the addition of $20 \mu \mathrm{M}$ nifedipine to the local superfusate at the recording site; the number of action potentials during the test pulse was unaffected by a preceding scratch episode $(n=5$; Fig. $2 B)$. This result suggests that motor network activity increases the excitability of motoneurons by facilitating L-type $\mathrm{Ca}^{2+}$ channels.
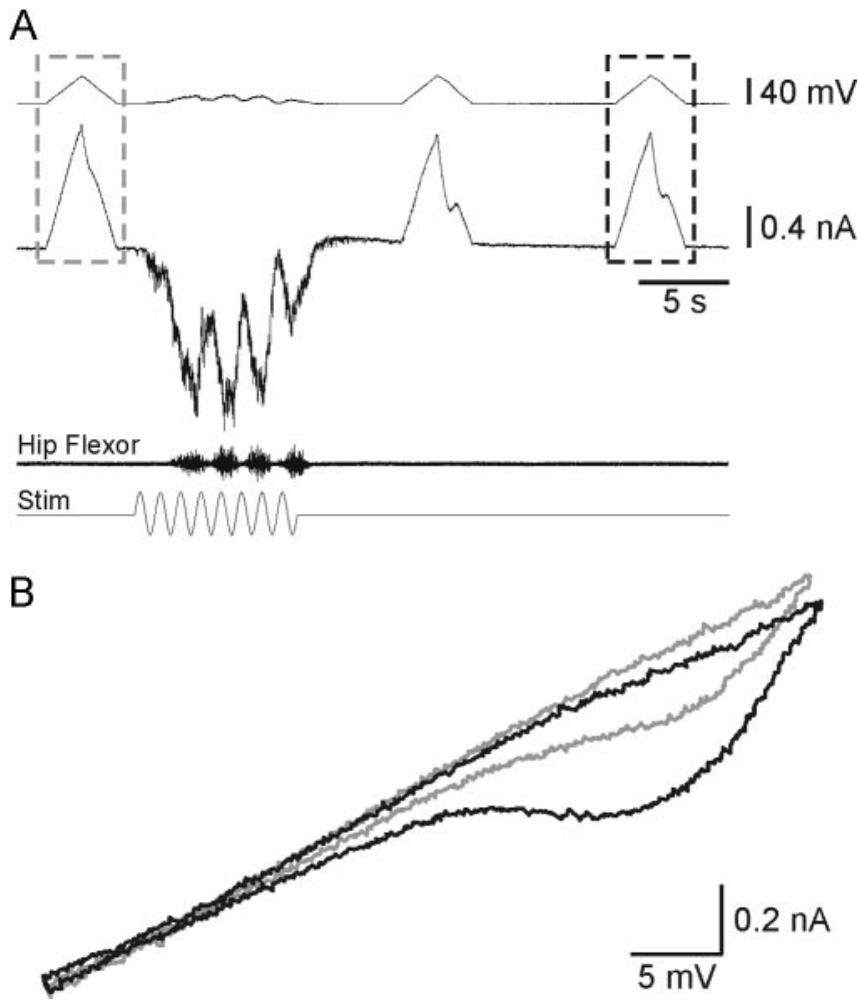

Figure 3. Motor network activity facilitates a slowly activating voltage-sensitive inward current. In voltage clamp the motor network activity facilitated a slow inward current activated by a depolarizing voltage command (top trace). When represented as a current-voltage relation (potential and current values from dashed box in $A$ ), the network activity increased the hysteresis of this relation $(B)$.

\section{mGluR1-mediated increase in motoneuron excitability}

In spinal motoneurons of the turtle several neurotransmitters promote plateau potentials by facilitating L-type $\mathrm{Ca}^{2+}$ channels (Hounsgaard and Kiehn, 1989; Svirskis and Hounsgaard, 1998). Isolated from the brainstem, the main candidate for facilitation of plateau potentials in a carapace-spinal cord preparation is glutamate. Previous experiments demonstrated that synaptically released glutamate facilitates L-type $\mathrm{Ca}^{2+}$ channels by activating group I metabotropic glutamate receptors (Delgado-Lezama et al., 1997). In the present experiments the mGluR1 antagonist CPCCOEt $(100 \mu \mathrm{M})$ added to the local superfusate at the recording site consistently abolished the increased excitability of motoneurons induced by motor network activity; the number of action potentials during the test pulse was unaffected by a preceding scratch episode $(n=5$; Fig. $4 A, B)$. This finding indicates that the facilitation is mediated by the activation of mGluR1.

\section{Discussion}

In this study we find that scratch-like motor network activity facilitates the PIC and increases the excitability of coactivated motoneurons. These effects depend on the activation of mGluR1 and involve the facilitation of L-type $\mathrm{Ca}^{2+}$ channels. Our findings show that glutamate is an intrinsic modulator in the spinal motor network.

Our experiments provide direct evidence for the presence of a PIC in spinal motoneurons in the isolated carapace preparation. Properties mediated by this current therefore contribute to motor behavior even in the absence of the facilitation that is mediated by descending serotonergic and noradrenergic modulation from the brainstem. 
A

\section{Control}

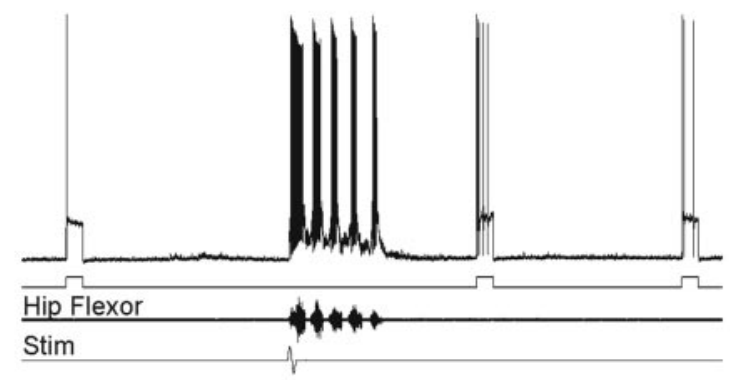

$\mathrm{B}$ + CPCCOEt

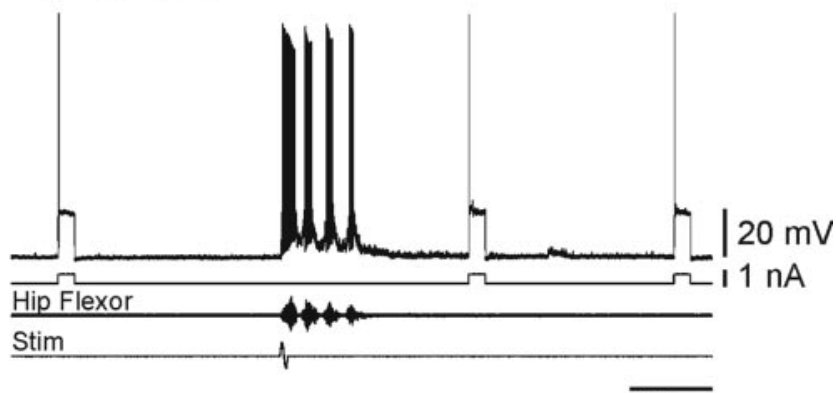

$\overline{10 \mathrm{~s}}$

Figure 4. mGluR1 mediates the increased excitability induced by motor network activity. The increased excitability in motoneurons that followed motor network activity $(A)$ was removed by the local application of CPCCOEt (100 $\mu \mathrm{m} ; B)$.

This shows that PIC in motoneurons is an active component in spinal motor activity in general, regulated by both extrinsic and intrinsic modulation (Katz and Frost, 1996). It should be noted, however, that, although PIC was facilitated by motor network activity, regenerative plateau potentials or signs of bistability were not observed in motoneurons during scratch-like episodes. This is in agreement with the observation that the voltage trajectory in motoneurons during scratch episodes is determined by excitatory and inhibitory synaptic potentials (Robertson and Stein, 1988).

Scratch episodes in vivo (Crowe and Linnartz, 1985; Currie and Stein, 1988) and in vitro (Currie and Lee, 1996) are followed by a prolonged enhancement of the motor response to certain forms of renewed stimulation. This residual excitability is associated with prolonged afterdischarges in a distinct population of interneurons (Currie and Stein, 1990). Our experiments show that, although synaptic activity and membrane potential return to resting levels within seconds after cessation of scratch motor nerve activity (Robertson and Stein, 1988), motoneurons remain hyperexcitable in response to depolarizations for tens of seconds. The facilitated PIC in motoneurons during scratch motor activity therefore seems to ensure a high level of excitability rather than rhythmicity during motor episodes.

The analysis critically depends on the ability to control selectively the extracellular environment around the motoneuron that was recorded from without affecting the motor network in general. This was achieved by separate perfusion of the spinal canal and superfusion of the cut surface that was recorded (Fig. $1 A$ ). In control experiments all synaptic potentials were eliminated from D10 motoneurons by the addition of antagonists of ionotropic receptors for glutamate, GABA and glycine. This did not affect the evoked scratch reflex recorded from the hip flexor nerve or abolish the facilitation of PIC in hip flexor motoneurons (our unpublished experiments).

PIC and the increased excitability that followed episodes of scratch-like motor activity were blocked by nifedipine and thus depended on L-type $\mathrm{Ca}^{2+}$ channels. The voltage dependence and the slow activation of the current in voltage clamp exclude a significant contribution of the $\mathrm{Ca}^{2+}$-activated nonselective cationic current and the fast, persistent $\mathrm{Na}^{+}$current also present in spinal motoneurons (Perrier and Hounsgaard, 1999; Lee and Heckman, 2001). The low activation threshold further suggests that the PIC studied here is mediated by the $\mathrm{Ca}_{\mathrm{V}} 1.3$ subtype of L-type $\mathrm{Ca}^{2+}$ channels (Carlin et al., 2000b; Perrier et al., 2002).

In motoneurons in a slice preparation of the turtle spinal cord, the activation of presynaptic axons led to the facilitation of L-type $\mathrm{Ca}^{2+}$ channels that depended on the activation of metabotropic receptors for serotonin, acetylcholine, and glutamate (DelgadoLezama et al., 1997). In the present experiments facilitation of the PIC was eliminated by CPCCOEt, a selective antagonist for mGluR1 metabotropic glutamate receptors that has no agonist or antagonist activity on mGluR5, group II and III mGluRs, or on NMDA, AMPA, or kainate receptors in concentrations up to 100 $\mu \mathrm{M}$ (Annoura et al., 1996; Casabona et al., 1997). In other cell types mGluR1 predominantly is located perisynaptically (Baude et al., 1993; Lujan et al., 1997). Combined with the restricted diffusion of glutamate in the turtle spinal cord (Skydsgaard and Hounsgaard, 1994), it seems likely that PIC is modulated by glutamate from terminals on motoneurons rather than by paracrine spillover from remote synapses. Taken together, this suggests that glutamate released from last-order interneurons during scratch network activity facilitates L-type $\mathrm{Ca}^{2+}$ channels in motoneurons.

It is well established that the intrinsic response properties of motoneurons are regulated by descending pathways from the brainstem (Conway et al., 1988; Hounsgaard et al., 1988; Krawitz et al., 2001). In addition to this extrinsic modulation, the present study establishes modulation as an intrinsic component of spinal motor network activity. This is a striking parallel to the well established extrinsic and intrinsic modulation in small motor networks in invertebrates (Katz and Frost, 1996) and developing vertebrates (Dale and Gilday, 1996; Grillner, 2003). It remains to be seen whether mixed ionotropic and metabotropic transmission is distributed evenly among glutamatergic synapses from last-order interneurons to motoneurons. Likewise, intrinsic modulation at other synapses in the spinal motor network needs to be investigated.

\section{References}

Annoura H, Fukunaga A, Uesugi M, Tatsuoka T, Horikawa Y (1996) A novel class of antagonists for metabotropic glutamate receptors, 7-(hydroxyimino)cyclopropa[b]chromen-1a-carboxylates. Bioorg Med Chem Lett 6:763-766.

Baldissera F, Cavallari P, Dworzak F (1991) Cramps: a sign of motoneurone "bistability" in a human patient. Neurosci Lett 133:303-306.

Baldissera F, Cavallari P, Dworzak F (1994) Motor neuron "bistability." A pathogenetic mechanism for cramps and myokymia. Brain $117[\mathrm{Pt}$ 5]:929-939.

Baude A, Nusser Z, Roberts JD, Mulvihill E, McIlhinney RA, Somogyi P (1993) The metabotropic glutamate receptor (mGluR1 $\alpha$ ) is concentrated at perisynaptic membrane of neuronal subpopulations as detected by immunogold reaction. Neuron 11:771-787.

Bennett DJ, Li Y, Harvey PJ, Gorassini M (2001a) Evidence for plateau potentials in tail motoneurons of awake chronic spinal rats with spasticity. J Neurophysiol 86:1972-1982.

Bennett DJ, Li Y, Siu M (2001b) Plateau potentials in sacrocaudal motoneurons of chronic spinal rats, recorded in vitro. J Neurophysiol 86:1955-1971. 
Carlin KP, Jiang Z, Brownstone RM (2000a) Characterization of calcium currents in functionally mature mouse spinal motoneurons. Eur J Neurosci 12:1624-1634.

Carlin KP, Jones KE, Jiang Z, Jordan LM, Brownstone RM (2000b) Dendritic L-type calcium currents in mouse spinal motoneurons: implications for bistability. Eur J Neurosci 12:1635-1646.

Casabona G, Knopfel T, Kuhn R, Gasparini F, Baumann P, Sortino MA, Copani A, Nicoletti F (1997) Expression and coupling to polyphosphoinositide hydrolysis of group I metabotropic glutamate receptors in early postnatal and adult rat brain. Eur J Neurosci 9:12-17.

Conway BA, Hultborn H, Kiehn O, Mintz I (1988) Plateau potentials in $\alpha$-motoneurones induced by intravenous injection of L-dopa and clonidine in the spinal cat. J Physiol (Lond) 405:369-384.

Crill WE, Schwindt P (1984) Ionic mechanisms underlying excitation-tofrequency transduction: studies by voltage-clamp methods. Arch Ital Biol 122:31-41.

Crowe A, Linnartz P (1985) Studies on the excitability of the central program generator in the spinal cord of the terrapin Pseudemys scripta elegans. Comp Biochem Physiol A 81:905-909.

Currie SN, Lee S (1996) Sensory-evoked pocket scratch motor patterns in the in vitro turtle spinal cord: reduction of excitability by an $N$-methyl-Daspartate antagonist. J Neurophysiol 76:81-92.

Currie SN, Stein PS (1988) Electrical activation of the pocket scratch central pattern generator in the turtle. J Neurophysiol 60:2122-2137.

Currie SN, Stein PS (1990) Cutaneous stimulation evokes long-lasting excitation of spinal interneurons in the turtle. J Neurophysiol 64:1134-1148.

Dale N, Gilday D (1996) Regulation of rhythmic movements by purinergic neurotransmitters in frog embryos. Nature 383:259-263.

Davenport J, Schwindt PC, Crill WE (1977) Penicillin-induced spinal seizures: selective effects on synaptic transmission. Exp Neurol 56:132-150.

Delgado-Lezama R, Perrier JF, Nedergaard S, Svirskis G, Hounsgaard J (1997) Metabotropic synaptic regulation of intrinsic response properties of turtle spinal motoneurones. J Physiol (Lond) 504[Pt 1]:97-102.

Grillner S (2003) The motor infrastructure: from ion channels to neuronal networks. Nat Rev Neurosci 4:573-586.

Hounsgaard J, Kiehn O (1985) $\mathrm{Ca}^{2+}$-dependent bistability induced by serotonin in spinal motoneurons. Exp Brain Res 57:422-425.

Hounsgaard J, Kiehn O (1989) Serotonin-induced bistability of turtle motoneurones caused by a nifedipine-sensitive calcium plateau potential. J Physiol (Lond) 414:265-282.

Hounsgaard J, Mintz I (1988) Calcium conductance and firing properties of spinal motoneurones in the turtle. J Physiol (Lond) 398:591-603.

Hounsgaard J, Hultborn H, Jespersen B, Kiehn O (1984) Intrinsic membrane properties causing a bistable behaviour of $\alpha$-motoneurones. Exp Brain Res 55:391-394.

Hounsgaard J, Hultborn H, Kiehn O (1986) Transmitter-controlled properties of $\alpha$-motoneurones causing long-lasting motor discharge to brief excitatory inputs. Prog Brain Res 64:39-49.

Hounsgaard J, Hultborn H, Jespersen B, Kiehn O (1988) Bistability of $\alpha$-motoneurones in the decerebrate cat and in the acute spinal cat after intravenous 5-hydroxytryptophan. J Physiol (Lond) 405:345-367.
Kao LI, Crill WE (1972) Penicillin-induced segmental myoclonus. I. Motor responses and intracellular recording from motoneurons. Arch Neuro 26:156-161.

Katz PS, Frost WN (1996) Intrinsic neuromodulation: altering neuronal circuits from within. Trends Neurosci 19:54-61.

Keifer J, Stein PS (1983) In vitro motor program for the rostral scratch reflex generated by the turtle spinal cord. Brain Res 266:148-151.

Krawitz S, Fedirchuk B, Dai Y, Jordan LM, McCrea DA (2001) Statedependent hyperpolarization of voltage threshold enhances motoneurone excitability during fictive locomotion in the cat. J Physiol (Lond) 532:271-281.

Lee RH, Heckman CJ (1999) Enhancement of bistability in spinal motoneurons in vivo by the noradrenergic $\alpha 1$ agonist methoxamine. J Neurophysiol 81:2164-2174.

Lee RH, Heckman CJ (2000) Adjustable amplification of synaptic input in the dendrites of spinal motoneurons in vivo. J Neurosci 20:6734-6740.

Lee RH, Heckman CJ (2001) Essential role of a fast persistent inward current in action potential initiation and control of rhythmic firing. J Neurophysiol 85:472-475.

Lennard PR, Stein PS (1977) Swimming movements elicited by electrical stimulation of turtle spinal cord. I. Low-spinal and intact preparations. J Neurophysiol 40:768-778.

Lujan R, Roberts JD, Shigemoto R, Ohishi H, Somogyi P (1997) Differential plasma membrane distribution of metabotropic glutamate receptors mGluR1 $\alpha$, mGluR2, and mGluR5 relative to neurotransmitter release sites. J Chem Neuroanat 13:219-241.

Melby ECJ, Altman NH (1974) Handbook of laboratory animal science. Cleveland, OH: CRC.

Perrier JF, Hounsgaard J (1999) $\mathrm{Ca}^{2+}$-activated nonselective cationic current $\left(I_{\mathrm{CAN}}\right)$ in turtle motoneurons. J Neurophysiol 82:730-735.

Perrier JF, Hounsgaard J (2000) Development and regulation of response properties in spinal cord motoneurons. Brain Res Bull 53:529-535.

Perrier JF, Alaburda A, Hounsgaard J (2002) Spinal plasticity mediated by postsynaptic L-type $\mathrm{Ca}^{2+}$ channels. Brain Res Brain Res Rev 40:223-229.

Robertson GA, Stein PS (1988) Synaptic control of hindlimb motoneurones during three forms of the fictive scratch reflex in the turtle. J Physiol (Lond) 404:101-128.

Rosenberg ME (1986) Carapace and plastron sensitivity to touch and vibration in the tortoise (Testudo hermanni and T. graeca). J Zool (Lond) 208:443-455

Sherrington CS (1906) Observations on the scratch reflex in the spinal dog. J Physiol (Lond) 34:1-50.

Skydsgaard M, Hounsgaard J (1994) Spatial integration of local transmitter responses in motoneurones of the turtle spinal cord in vitro. J Physio (Lond) 479([Pt 2]:233-246.

Stein PS, Grossman ML (1980) Central program for scratch reflex in turtle. J Comp Physiol 140:287-294.

Svirskis G, Hounsgaard J (1998) Transmitter regulation of plateau properties in turtle motoneurons. J Neurophysiol 79:45-50.

Valk-Fai T, Crowe A (1978) Analyses of reflex movements in the hind limbs of the terrapin Pseudemys scripta elegans. J Comp Physiol 125:351-357. 